\title{
The Students' Attitudes towards the Use of Code Switching and the Different Types that Occur in Speech
}

Received: 29/09/2019 ; Accepted: 09/12/2019

\section{Abstract}

This work aims at investigating the different types of code switching and the students' attitudes towards the use of this phenomenon. The study is conducted at the department of Letter and Arabic languages, ENSC in Constantine and it involves 50 speaking students to answer the questionnaire concerning the attitudes of using code switching and a direct observation is made in which it entails the researcher to assist to different sessions and recording the conversations in order to identify the different types of code switching that occur during the interactions.

Keywords: code switching phenomenon, attitudes of code switching and types of code switching, ENSC students.
Nachoua KELKOULA *

Pr. Farida DJAILEB

Mohamed Ben Ahmed Oran University

\section{Résumé}

Ce travail vise à étudier les différents types de changement de code et les avis des étudiants visà-vis de l'utilisation de ce phénomène. L'étude est menée au département de langues lettre et arabe de l'ENSC à Constantine. Elle implique 50 étudiants qui ont été choisis pour répondre au questionnaire et une observation directe est faite. Le chercheur assiste à différentes sessions et enregistre les conversations afin d'identifier les différents types de changement de code qui se produisent pendant les interactions.

Mots clés: les étudiants de l'ENSC, changement de code, les types des codes et les avis concernant ce phénomène.

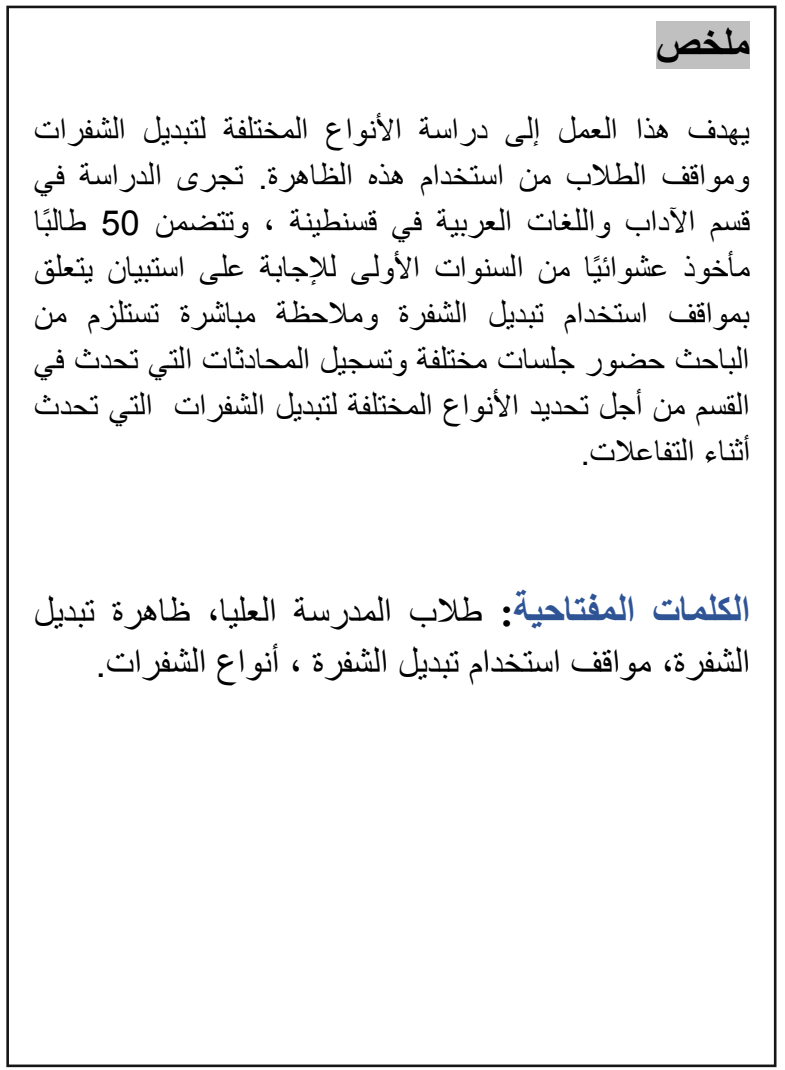

* Corresponding author, e-mail: nashwaeline@outlook.fr 


\section{Introduction}

As human beings, we always tend to express our thoughts, ideas and emotions through languages. It is commonly agreed that the use of two or more languages in the same conversation occurs in bilingual or multilingual communities. The term that is used to describe such language contact is referred to as code -switching. Code switching is a familiar linguistic phenomenon used in countries where bilingual or multilingual speakers communicate with more than just one language or variety in everyday interactions. In fact, code switching becomes a common practice among all bilingual and multilingual societies all over the world in that in each country we may find at least two languages or varieties of language spoken. The phenomenon of code switching has been a subject of many writers, linguists and researchers such as Myers Scotton (1991); Poplack (1980); Milroy and Muysken (1995) and so many others. Myers and Ury (1977) for example, defined code switching as "the use of two or more linguistic varieties in the same conversation or interaction". Various studies have been made to investigate and scrutinize the occurrence, the reasons and the functions, the types and the attitudes of code switching and various theories have been put forth about what code switching really is and what motivates bilingual or multilingual speakers to code switch. Algeria, like any other Arab countries is characterized by the existence of different sociolinguistics phenomena because of the distinct languages and the various varieties that are spoken and used by Algerians and the contact between them. In fact, code switching is one of the features that is well observed and highly used among Algerians compared to other Arab speakers in that if strangers come to Algeria to observe what an Algerian repertoire could consist of, they would be very surprised about the richness and the linguistic diversity in this country. Many languages and varieties are dominant in Algeria; this co existence of genetically unrelated languages makes Algeria a bilingual and even multilingual community. This study attempts to identify the different types of code switching and the attitudes of students concerning the use of this phenomenon in classes.

The significance of this study lies in the fact that no other studies have been conducted in the same setting and exploring the same reasons or objectives. When we talk about setting, we mean conducting a research in Letters and Arabic languages Department. This paper will add to the existing literature on code switching and information gained from this research will provide insights on how and why code switching occurs in classrooms of Letters and Arabic languages Department. Due to the increasing interest in the studies of code switching in classes over the past two decades, this study will focus on code switching in the department of Arabic at ENSC school and reveal whether its use in classroom is counterproductive or not and whether students studying literature are truly less code switchers compared to other students who study English, French or Spanish languages, or those who are in medicine, mechanic and engineering branches.

\section{Literature Review}

In sociolinguistics studies, the term "code switching "is a linguistic conversational phenomenon which generally refers to the alternation of two different languages or varieties within the same sentence or discourse. In fact, code switching is a natural process that occurs among bilingual or multilingual speakers who often tend to switch between their languages while conversing for special purposes. Many linguists and sociolinguists talked about this concept and each one examined it from various angles and from his or her own perspective; yet there is no clear and definite definition of what code switching actually is and where does it occur because the term is of a great ambiguity. Jacobson (1990, p.1) writes about this discrepancy as follow:

The notion of alternation between varieties is not conceived of in a homogenous way, but, rather, that different investigators examine the phenomenon in ways that elude the possibility of providing a definition of code switching that all will subscribe to. 
Haugen (1956) was the first to use the term "code switching" referring it to the alternation and interference between two or more languages by bilingual speakers and Crystal (1987, p.363) points out that 'as the definition of 'language' is tenuous at best, perhaps it is better to say switching between varieties in addition to switching between languages" So, we understand that switching can occur not only between languages but also dialects or varieties of the same language. In the same line of thought, Milroy and Muysken (1995, p.7) define code switching as "the alternative use by bilinguals of two or more languages in the same conversation." and they perceive code switching as "a cover term that includes different forms of bilingual behavior". However, Bentahila and Davies (1983) give a more comprehensive definition of code switching. They write:

We shall henceforth use the term code -switching to refer to the use of two languages within a single conversation, exchange or utterance. The result is an utterance or interaction of which some parts are clearly in one of the bilingual's languages and other parts in the other language. (315)

Furthermore, Gumperz (1982, p.59) defines code switching as "the juxtaposition within the same speech exchange of passages of speech belonging to two different grammatical systems or subsystems". In fact, Gumperz studied code switching relating it to social situations in which the focus was on the communicative functions of the codes that are being used in such bilingual situations. He claims that each code has a certain communicative function in a society and that these codes are sustained separate by the members of the community giving an illustration of the two dialects (Bokmal and Ranamal) in Norway, where the speakers of this Hemnesberget village think themselves are code switching, while, in reality, they were in a case of dialect continuum of the same language.

Hymes 1968 on the other hand describe this phenomenon as a form of incompetence in one language. In fact, sometimes bilingual or multilingual speakers tend to shift from one language or from one code to another when they feel unable to find a right word or a particular expression to convey what they are trying to say or to fully express themselves. In this sense Hymes says that code switching is "used as a strategy of communication to compensate his lack of competence by using sometimes one language, sometimes the other to maximize the efficiency of the communications. (p. 200).

Different definitions have been given to code switching and many writers and linguists agree that the term is still ambiguous but we can clearly observe from the different views that code switching refers to the process of shifting between two languages or dialects by bilingual or multilingual speakers in the same conversation or within the same speech ( Garden, 2009).

Many researchers and analysts have been asking questions such as: why does the pattern of switching occur, what are the functions of code switching in bilingual discourse and what is the reason behind it? In fact, these researchers tried several times to find at least one single motivator behind code-switching but the thing is sometimes there is no motivator at all. Thus, it is important to know that bilinguals may code switch between languages without being aware of the fact that they are doing so. In this sense, Bullock and Toribio 2010 say:

...it merits pointing out that not all language alternations in bilingual speech do signal a particular communicative intent or purpose: for many bilinguals, codeswitching merely represents another way of speaking; that is, some bilinguals' code-switch simply because they can and often times may not be aware that they have done so. (p. 11)

Scholars and researchers have observed many types of code switching and tried to give a typology of such a phenomenon. Code switching can be of three major types namely: situational code switching, metaphorical code switching and conversational code switching. In fact, Bloom and Gumperz 1972 identified only two patterns of code switching while making their ethnographic study from a functional view in a town in Norway. The types include situational CS and metaphorical Cs, but Gumperz, later on, developed the third pattern which is called "conversational CS". From other perspective, some linguists distinguish three other types of switching and 
these types ca ne be derived from utterances .Poplack (2000) for example proposes these types to include intersentential code switching, intrasentential code switching and tag switching In the same vein, Myers-Scotto 1993 categories these three types according to place of occurrence in speech.

\section{- Inter-Sentential Code Switching}

Inter sentential code switching refers to the type of switching in which speakers move from one language to another between different sentences or clauses in that one sentence or clause will be uttered in one language while the other sentence or clause would be in a completely different language. This means that speakers should be fluent in both languages and must have the ability to follow the rules of these two languages.

\section{- Intra-sentential Code Switching}

Intra sentential code switching is regarded as the most complex form of switching since its occurrence "may be avoided by all but the most fluent bilinguals" (romaine, 1985, p.113) and since the shift occurs within the same sentence or in the middle of the sentence with no hesitations, interruptions or any kind of pause which may indicate a shift. In this sense Myers (1993, p.3) says that "intra-sentential switching occurs within the same sentence or sentence fragment". Speakers in this case tend to move from one language to another within the same sentence. Thus, in one sentence we may observe two or more different languages. In his study of code switching, Poplack (1980) gave the following example to explain what sort of types this include. He stated: "sometimes I'll start a sentence in English y termino en espanol" which means (sometimes, I'll start a sentence in English and finish in Spanish). Actually, this type of code switching needs a really high degree of fluency because switchers are required to shift to the rules of syntax. Winford (2003) claims that there are some researchers who do not consider this type of switching as proper code switching, rather they consider it as code mixing.

\section{- Tag Switching}

According to Romaine (1995, p.22), tag switching refers to “(...) the insertion of a tag in one language into an utterance which (...) is in the other language". This type of code switching is very simple because it involves the inclusion of a tag or any short phrase in one language into an utterance which is in another language. Romaine (1995) points that tags are "subject to minimal syntactic restrictions", with no violation of the grammatical rules. Therefore, tag switching involves discourse markers, interjections, fillers, idiomatic expressions and single noun switches such as: "you know", "I mean", "right", "well”, "ok" and so on. Romaine (1989) has provided the following example to explain this type of switching: "es difficil encontrar trabajo estes dias, YOU KNOW? Which means: (It is hard to find work these days, you know?).

Attitudes towards the phenomenon of code switching differ from one person to another. In fact, there are two positions towards code switching: positive and negative attitudes. There are some bilinguals who support the use of code switching whether be it in everyday life or in education and teaching justifying this use by the fruitful benefits they gain, whereas some others find it deeply pretentious and almost unnecessary and a big number of researchers through literature agreed on the negative side of code switching.

According to some studies, bilinguals who switch code between languages themselves believe that code switching is an indicator of either laziness or poor proficiency and as a sign of 'showing off'. In fact, many researchers used pejorative terms for code switching such as: 'verbal salad', 'still colonized', 'very irritating', 'very annoying' and 'semilinguisme double' In their studies, Chana and Romaine (1984) came up with negative attitudes towards the Code switching among PunjabiEnglish bilinguals and Bentahila (1983) reported negative attitudes of Arabic -French bilinguals in Morocco and their attitudes ranged from pity to disgust. The negative attitudes towards code switching lead people to attenuate their self- reported code 
switching like what happened with the Norwegian participants who underreported the amount of code switching they engage in (Bloom and Gumperz 1972) and the bad thing about this is that most people who code switch do not really acknowledge it ( Romaine 1995).

On the contrary, some other researchers in the field of sociolinguistics believe that code switching is an important aspect of language since it has an effective role in conveying the meaning and transmitting the message. Dewaela (2010, p.201) for example states that code switching is "not an indication of a deficit in the LX but on the contrary a characteristic of participants who feel proficient in their LXs"'. Some researchers in the educational field such as Cook (2001) and Skiba (1997) believe that the use of code switching in classroom is 'a legitimate strategy' and it provides a good chance for language development.

Code switching in North African Arabic is a phenomenon that has attracted the attention of many researchers and that has been a study of by linguistics because North Africa was the home to different cultures and various occupations. In fact code switching is becoming more and more common in North Africa in general and in Algeria in particular. In Algeria, code switching is an observed common practice which occurs every day among the speakers who shifts from one language to another or from one variety to another while conversing. In fact, Algeria is a bilingual and multilingual community where a myriad of languages co-exist and work together. The use of five different varieties in correspondence to two settings which are formal and informal raises a complex linguistic situation in Algeria. This situation in turn is seen different from the situations of other countries of the Arab World.

Code switching in Algeria usually occurs between Algerian Arabic and French or between Berber and French because of some historical factors. In fact, the colonization of French which took 132 years influenced Algeria in that French has been deeply rooted in the Algerian society and it still keeps playing a note worthy role in all domains. It is not surprising that most Algerian speakers use Arabic and French or Berber and French within the same conversation. In this sense, the journalist Mohamed Amghar writes in "El Moudjahed" (February 8 th, 1974) as quoted by Bouamrane (1986, p.109):

They speak to you two minutes in French, 30 seconds in Arabic then one minute in French and so on, sometimes the two languages are mixed to such a point that the results are bizarre, unintelligible language, and one wonders if these people are not themselves bizarre.

One cannot judge people as being bizarre or whatever because of the mixed languages they speak or use. It is not the Algerians' fault that the linguistic situation is very intricate, one should know. In fact, the true problem is based on the fact that the Algerian government could not succeed to adopt a right policy or an appropriate system to arabise the country and get rid of the colonialist languages.

The majority of speakers switch back and forth from Algerian Arabic to French or from Berber to French in their daily utterances. But there are also shifts from Algerian Arabic to Modern Standard Arabic. Poplack (1980) distinguished three types of code switching. We will try to apply them in the Algerian context:

$\checkmark$ Inter-sentential switching: this type of switching occurs at sentence or clause boundary. In the Algerian case for example, when someone starts a sentence in the French and finishes it in Algerian Arabic or Berber, we call it an Intersentential switching. Let's consider the following sentence:

- Elle nous a demandé d'allumer la télévision/ beh ntfarjou el mousalsal/

(She asked us to turn on the televison in order to watch the series).

- Je vais dormir ma chérie, thirga el 3ali.

(I am going to bed my dear, good night).

- Had tafla 3andha 9oudourat sihriya khari9a

(This girl has super magical powers)

$\checkmark$ Intra-Sentential Switching: holds that switching occurs within the clause or sentence boundary as in: 
- Rayha l'agence nreservi beh n3agab les vacances.

(I am going to book at the agency in order to spend holidays.)

- Rahi fi tahasoun malhoud besah lazamha el 3amal w elmoutabara.

(She is in a remarkable improvement but she needs to work and preserve hard)

$\checkmark$ Tag Switching: the insertion of a tag in one language into an utterance which is in the other language. Consider the following examples:

- 9ala9tini bazaf, tu Sais?

(You bothered me a lot, YOU KNOW?)

- Fahmagh takvaylit, d'accord?

(I understand Kabyle, OK?)

Most Algerian speakers use a long list of French words to the point that one could easily be confused whether it is French or Arabic. Examples of such words include: cava, ca yest, c'est bon, déjà, voila, c'est grave, normal, jamais and so on. Furthermore, various new words are found in the Algerian society; these words are related to technology development and they have no equivalent in Algerian Arabic such as flexy, connecter, chater, taper, désactiver, en ligne, hors ligne, and so on. It is also important to highlight here that after the arabisation process the use of MSA has developed increasingly among Algerian speakers. It is not suprising therefore, to hear someone saying /layla sa3ida/ salam/ talab khati/ istid3aa/ instead of the French words: bonne nuit, salut, demande, and convocation.

\section{Methodology}

The study was conducted at the Department of letters and Arabic languages in ENSC. All the participants in this study are of Algerian nationality but coming from different regions of the country such as: Guelma, Setif, Bejia, Khanchla, Algiers, Mila etc...The whole population of the students studying in first year in letters and Arabic language Department is 120 students. 50 students were chosen randomly from different classes of first year to answer the questionnaire concerning the attitudes towards the use of code switching. Out of the chosen 50 participants, 45 of them are female while the remaining five are male. These students are asked to answer 15 questions of different types; closed questions, open- ended questions and clarification questions. In addition to this, the method that was employed in collecting data in this study is direct observation and type recordings. It entails the researcher to assist to different sessions and recording the conversations that take place in the classroom. The researcher selected a particular module which was noted for interactive activities to be observed intensively. A class of 30 students of first year was chosen in order to observe when students code switch and to identify the types of code switching that occur during the conversation. The observations were based on an observational framework adapted from Poplack's (1980) patterns of code switching.

\subsection{Results and Findings}

\section{$\checkmark$ The Interpretation of the Students' Questionnaire}

The aim of this questionnaire is to find out the students' opinion about code switching; whether students show positive, negative or neutral attitudes towards the use of two languages (Algerian Arabic and French). According to the results, most students express that using code switching in life and mainly in classroom environment is very effective and only few students think that code switching is not effective at all. Based on the number of response, it can be expected that most student are aware of the use of code switching in classroom. Then answering the question "how", we can state here below students who give some justifications. Some students mention that code switching in classroom help to express ones' self and present pragmatic meaning. 
Others say that code switching induces a relaxed class atmosphere that allows students to participate and perform better. One student claims that code switching in classroom fosters a good and positive ambience and another one comments that code switching helps to bridge communication gap in the classroom. Some of them believe that code switching saves time to explain, thus it helps to understand quickly and better. Other replying students see code switching as a beneficial tool for teachers to explain difficult terms or concepts for the students if the aim is to make meaning crystal clear and to transfer the knowledge in an efficient way. In addition to this, the big majority of the students adopt the positive attitude, which is as far as we know the most agreed upon literature. Lots of students give positive opinion about the use of code switching in classes and they want it to be an integral strategy for most teachers because of its importance and indispensability. Out of 50 students, only 3 students have contradictory opinion; they show negative attitude towards the use of code switching and they consider it as inappropriate manners in classroom and especially towards the teachers. It is important to know that despite these negative attitudes, all these respondents are themselves code switchers since they do code switch between Arabic and French unconsciously in some situations. Two students' point of view towards code switching has been neutral. This means that these students do not know whether it is good or bad to code switch in classes, tough they are aware of the fact that they often code switch with their classmates and teachers. Moreover, many respondents support and encourage the idea of using code switching in classroom, however only 08 students discourage utilizing code switching because they consider this as an inappropriate action as they stated " especially as a teacher, he should not mix his utterances".

\section{$\checkmark$ The interpretation of the type recording and the direct observation}

The frequency of occurrence of code switching between students was high in that there was at least one instance of code switching in each conversation. Intra-sentential code switching was the most frequent one and inter-sentential was the least used type recorded in the data analyzed. The table below shows the number of instances and the frequency of occurrence of each type of code switching in our data.

\begin{tabular}{|l|l|l|l|}
\hline Rank & Type & counts & Percentages \\
\hline $\mathbf{1}$ & Intra-sentential CS & $\mathbf{1 1 8}$ & $66.29 \%$ \\
\hline $\mathbf{2}$ & Tag switching & $\mathbf{5 0}$ & $28.08 \%$ \\
\hline $\mathbf{3}$ & Inter-sentential CS & $\mathbf{1 0}$ & $5.61 \%$ \\
\hline Total & $/$ & $\mathbf{1 7 8}$ & $\mathbf{1 0 0 \%}$ \\
\hline
\end{tabular}

Table 1: rank order counts and percentages of CS types

\section{frequency.}

Instances of inter-sentential code switching were very few in number (10) compared to the other two types. On the other hand tag switching is less in number compared to the high frequent use of intra-sentential code switching. The following examples said by students when discussing and conversing between each other represent intra- sentential code switching which was found to be the most frequent types used in the data collected.

Example: labnat wesh tgolo fel 3ouhda al khamsa? ha9i9atan, ana jamais de ma vie, chaft president yahkam blad 20 ans.

Translation: girls, what do you say about the fifth mandate? Truly, I've never seen in my life, a president that governs a country for 20 years. example:

Tag switching was the second used by ENSC students. Consider the following

Example: Galou beli Bouteflika twafa, c vrai?

Translation: they said Bouteflika died, is it true?

The last following example is extracted from the data as example of intersentential code switching where students give full sentences or clauses in the subordinate language together with a sentence in the matrix language.

Example: capable oui, 1 'essential hna ndiro li 3lina.

Translation: possible yes, anyway, we have to do what it should be done. 


\section{Conclusion}

In this study, the phenomenon of code-switching between French and Algerian Arabic at ENSC was analyzed using a functional approach. The analysis of the recorded conversations demonstrated that almost all sentences start in one language, and then they shift directly to another language. All the three types suggested by Paplock were identified at ENSC, Letter and Arabic Languages Department and the most used one is the intra- sentential code switching. Moreover, the results elucidated that students have positive attitudes towards the use of code switching in classroom. They think that there is no harm about alternating the languages, rather they find it very beneficial and fruitful and some students want their teachers to adopt code switching as a tool or a strategy to be used in classroom but with moderation. Many Algerian researchers proved that code switching has bad and negative aspects in the classroom and the use of it should be banned. However, this work has proved the opposite and as Zentella (1981) express: "it seems premature to bane code switching from the classroom when we do not know what we are banning along with it".

\section{REFRENCES}

Bentahila, A., \& Davies, E. D. (1983). "The Syntax of Arabic-French Code Switching”. Lingua, 59, 301-330.

Bullock, B. \& Toribio, A. (2010). Themes in the Study of Code-switching. In B. Bullock \& A. Toribio. (eds.) The Cambridge Handbook of Linguistic CodeSwitching. Cambridge: Cambridge University Press.

Blom, J. P., \& Gumperz, J. J. (1972). Social meaning in linguistic structures: Codeswitching in Norway. In L. Wei (Ed.), The bilingualism reader, (pp. 111 136). London: Routledge

1-Crystal, D. (1987). The Cambridge Encyclopedia of Language. Cambridge: Cambridge University Press.

2-Gardner-Chloros, P. (2009). Code-switching. Cambridge: Cambridge University Press.

3-Gumperz, J, J. (1982). Discourse Strategies. New York, NY: Cambridge University Press

4-Haugen, E. (1956). Bilingualism in the Americas: A Bibliography and Research Guide. Publications of the American Dialects Society 26.

5-Hymes, D. (1977). Foundations in sociolinguistics. London: Tavistock. 98 Hymes, D. H. (1962). Models of the interaction of language and social life. In J. J. Gumperz \& D. H. Hymes (Eds.), Directions in sociolinguistics: The ethnography of communication (pp. 35-71). New York: Holt, Rinehart \& Winston.

6-Jacobson, R. (ed.) (1990). Code switching as a Worldwide Phenomenon. New York: Peter Lang

7-Milroy, I. \& Muysken, P. (1995). Introduction: code switching and bilingualism research. In L. Milroy \& P. Muysken (Eds), one speaker two languages: Crossdisciplinary perspective on code switching (pp. 1-14). New York: Cambridge University Press.

8-Myers-Scotton, C. (1988). Codeswitching as indexical of social negotiations. In M. Heller (Ed.), Codeswitching: Anthropological and sociolinguistic perspectives (pp. 151-86). Berlin: Mouton de Gruyter. Myers-Scotton, C. (1993). Duelling languages: Grammatical structure in codeswitching. Oxford: Clarendon Press. 
9-Poplack, S. (1980). “Sometimes I'll start a sentence in English y termino en español: Toward a typology of code-switching”. Linguistics, 18, 581-618.

10-Romaine, S. (1995). Bilingualism. Oxford: Blackwell.

11-Zentella, A.C ( 1981). Ta bien, you could answer me en cualquier idioma : puerto Rican codeswitching in bilingual classrooms. In R. Duran (Ed), Latino language and communicative behavior (pp. 109-131). Norwood, NJ : Ablex

\section{Appendices:}

\section{Appendix one:}

\begin{tabular}{|l|c|c|c|}
\hline Rank & Type & counts & Percentages \\
\hline $\mathbf{1}$ & Intra-sentential CS & $\mathbf{1 1 8}$ & $66.29 \%$ \\
\hline $\mathbf{2}$ & Tag switching & $\mathbf{5 0}$ & $28.08 \%$ \\
\hline $\mathbf{3}$ & Inter-sentential CS & $\mathbf{1 0}$ & $5.61 \%$ \\
\hline Total & $/$ & $\mathbf{1 7 8}$ & $\mathbf{1 0 0 \%}$ \\
\hline
\end{tabular}

Source: rank order counts and percentages of CS type's frequency. 